\title{
Effect of Current and Atomized Grain Size Distribution on the Solidification of Plasma Transferred Arc Coatings
}

\author{
Danielle Bond ${ }^{2 *}$, Ana Sofia Clímaco Monteiro D'Oliveira ${ }^{b}$ \\ ${ }^{a}$ Sociedade Educacional de Santa Catarina - SOCIESC, \\ Universidade do Estado de Santa Catarina - UDESC, Rua Paulo Malschitzki, s/n, \\ Campus Universitário Professor Avelino Marcante, Zona Industrial Norte, \\ CEP 89219-710, Joinville, SC, Brazil \\ ${ }^{\mathrm{b}}$ Departamento de Engenharia Mecânica, Setor de Tecnologia, Centro Politécnico, \\ Universidade Federal do Paraná - UFPR, CP 19011, Jardim das Américas, \\ CEP 81531-990, Curitiba, PR, Brazil
}

Received: December 9, 2011; Revised: May 24, 2012

\begin{abstract}
Plasma Transferred Arc (PTA) is the only thermal spray process that results in a metallurgical bond, being frequently described as a hardfacing process. The superior properties of coatings have been related to the fine microstructures obtained, which are finer than those processed under similar heat input with welding techniques using wire feedstock. This observation suggests that the atomized feedstock plays a role on the solidification of coatings. In this study a model for the role of the powders grains in the solidification of PTA coatings is put forward and discussed. An experiment was setup to discuss the model which involved the deposition of an atomized Co-based alloy with different grain size distributions and deposition currents. X-ray diffraction showed that there were no phase changes due to the processing parameters. Microstructure analysis by Laser Confocal Microscopy, dilution with the substrate steel and Vickers microhardness were used the characterized coatings and enriched the discussion confirming the role of the powdered feedstock on the solidification of coatings.
\end{abstract}

Keywords: coatings, atomized, pulsed current

\section{Introduction}

Plasma Transferred Arc (PTA) is the only thermal spray process that results in a metallurgical bond with the substrate steel. As the atomized feedstock crosses the plasma arc and the particles melt a thermal spray forms and the energy of the arc also forms a melt pool in the substrate steel. As the melted particles reach the melt pool and solidify a dense coating with a strong bond to the substrate forms. The characteristics of PTA coatings that contribute to their superior performance include their low dilution with the substrate and fine microstructures. The latter has been explained when comparing coatings processed with other hardfacing processes due to the faster solidification rates imposed by PTA and therefore finer microstructures formed due to a faster growth rate ${ }^{1-4}$. However, a more accurate correlation had to involve deposition procedures with similar heat input as suggested in a previous work on the characterization of PTA coatings processed with a wire and an atomized feedstock alloy ${ }^{5,6}$. The microstructures as observed in the transverse section of coatings exhibited similar characteristics with a planar region near the fusion line followed by a columnar and a dendritic structure but a finer structure formed in the coatings processed with the atomized alloy. The similar solidification rates, imposed by the same processing parameters used suggest that nucleation is the determining stage on the development of

*e-mail: dbond@onda.com.br the finer structures. Evidences raised the hypothesis that the temperature of particles in the plasma arc will determine the nucleation rate: droplets can merge with the melt pool which will solidify as a bulk or solidify immediately after reaching the melt pool, acting as nuclei and contributing to the observed structure refinement. That being the case, the grain size distribution of the powders is a variable that needs to be considered when optimizing deposition procedures. To analyze this hypothesis the authors put forward a model on the role of the powder grains in the solidification of coatings and an experiment set up and the validation of the model discussed.

The paper aimed at understanding the role of the atomized feedstock on the solidification of coatings whether or not grain size distribution has to be considered as one of the processing variables when hardfacing with Plasma Transferred Arc.

\section{The Model}

The solidification of coatings processed with atomized alloys is influenced by the temperature that each atomized particle reaches in the plasma arc, which is determined by the particle grain size and processing parameters. The behavior of each particle as it crosses the plasma arc will fit within one of the five groups described below depending on its grain size, Figure 1. 


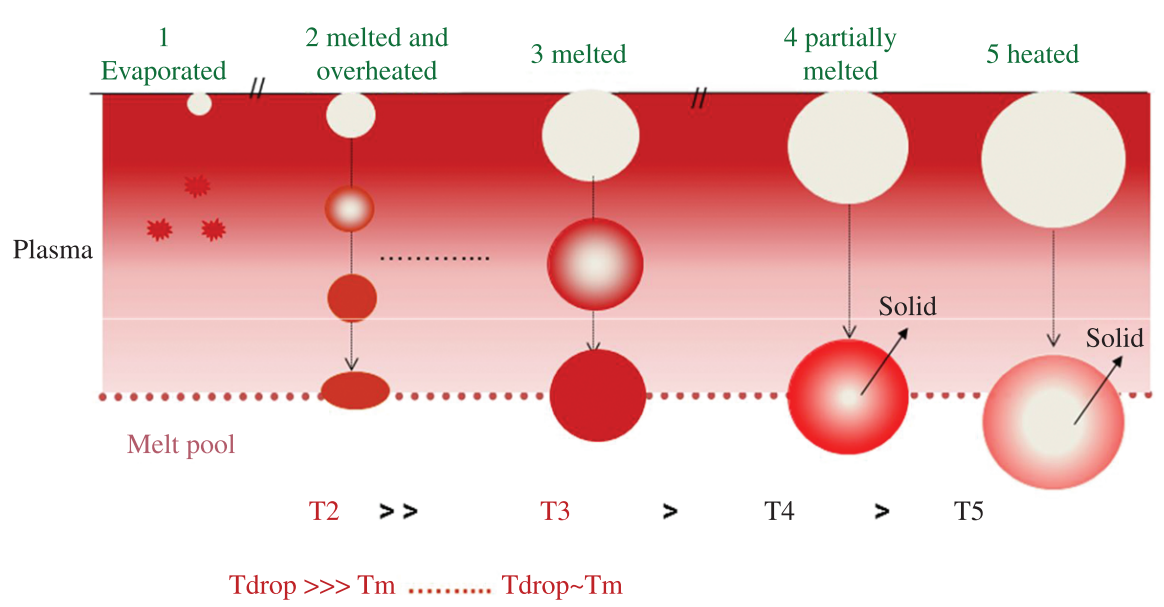

Figure 1. Effect of particle size on their temperature in the plasma arc.

1 - Evaporation - for very small particles crossing the central region of the plasma arc; these particles do not reach the melt pool.

2 - Melting and overheating - particles will reach the melted pool with a temperature well above melting temperature of the material and merge with the melt pool.

3 - Melted - particles will reach the melted pool with a temperature similar to the melting temperature of the material.

4 - Partially melted - particles will reach the melt pool partially melted; depending on the melt pool temperature they can subsequently melt and be incorporated in the melt pool or act as a nuclei and solidify.

5 - Heated - particles will not melt in the plasma arc either because of their large size, processing parameters or cross through the lower temperature regions of the plasma arc. Typically these particles will generate defects in coatings.

A typical grain size distribution includes particles within groups 2, 3 and 4. However, fractured of particles during handling of the atomized alloy and very dense, high melting temperature materials could result in the behavior described by group 5 . Although this study aimed at evaluating the effect of current and atomized grain size distribution, the temperature of particles when they reach the melt pool, may also be influenced by the procedure used to feed the powder metal into the plasma column (internal, external) as well as the travelling time of particles through plasma, and the type of nozzle constrictor?

\section{Experimental Procedure}

In order to test the proposed model an atomized Co-based alloy with the composition shown in Table 1 was deposited by Plasma Transferred Arc on AISI 1020 plates $(100 \times 100 \times 12,7 \mathrm{~mm})$.

Two sets of experiments were carried out to induce changes in the temperature of particles as they crossed the plasma arc:

- Different processing parameter: Changing the deposition current, Table 2, will alter the energy of the arc and as a consequence the temperature that each particle reaches as it crosses the arc;
Table 1. Chemical compostion of the Co-based alloy.

\begin{tabular}{cccccccc}
\hline $\mathbf{C o}$ & $\mathbf{C r}$ & $\mathbf{W}$ & $\mathbf{C}$ & $\mathbf{S i}$ & $\mathbf{M n}$ & $\mathbf{N i}$ & $\mathbf{F e}$ \\
\hline Bal. & $28 \%$ & $4.5 \%$ & $1.2 \%$ & $1.1 \%$ & $1 \%$ & $\begin{array}{c}\text { máx } \\
3 \%\end{array}$ & $\begin{array}{c}\text { máx } \\
3 \%\end{array}$ \\
\hline
\end{tabular}

Table 2. Deposition current used to induce changes in the temperature of particles in the plasma arc.

\begin{tabular}{ccc}
\hline Current mode & \multicolumn{2}{c}{ Intensity } \\
\hline Constant current & $\mathbf{1 0 0} \mathbf{A}$ & $\mathbf{1 4 0} \mathbf{A}$ \\
\hline \multirow{2}{*}{ Pulsed current } & $\mathrm{Ib}=75 \mathrm{~A}$ & $\mathrm{Ib}=75 \mathrm{~A}$ \\
& $\mathrm{Ip}=140 \mathrm{~A}$ & $\mathrm{Ip}=218 \mathrm{~A}$ \\
\hline
\end{tabular}

Table 3. Grain size range used to test the influence of particle size on the temperature of particles in the plasma arc.

\begin{tabular}{lcc}
\hline \multicolumn{1}{c}{ Powder distribution } & \multicolumn{1}{c}{$\begin{array}{c}\text { Deposition } \\
\text { current }\end{array}$} \\
\hline $\begin{array}{l}\text { Atomized alloy with particle size range: } \\
45-180 \mu \mathrm{m}-\text { reference alloy } \\
35 \mathrm{wt} . \%) \text { of } 45 \mu \mathrm{m} \text { particles added to the } \\
\text { atomized alloy }(45-180 \mu \mathrm{m})\end{array}$ & $100 \mathrm{~A} \quad 140 \mathrm{~A}$ \\
\hline
\end{tabular}

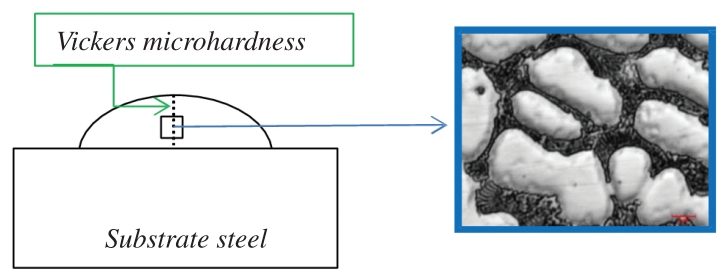

Figure 2. The transverse section of coatings to analyze microstructural changes and Vickers microhardness measurements.

- Different grain size distributions: Finer particles were added to the original grain size distribution, Table 3; finer particles should reach higher temperatures in the arc. 
Table 4. Plasma Transferred Arc processing parameters.

\begin{tabular}{cccccc}
\hline $\begin{array}{c}\text { Stand-off } \\
\text { distance }\end{array}$ & $\begin{array}{c}\text { Plasma gas flow } \\
\text { (Ar) }\end{array}$ & $\begin{array}{c}\text { Protection gas flow } \\
(\mathbf{A r})\end{array}$ & $\begin{array}{c}\text { Feeding gas flow } \\
(\mathbf{A r})\end{array}$ & Torch velocity & Feeding rate \\
\hline $10 \mathrm{~mm}$ & $2 \mathrm{~L} / \mathrm{min}$ & $15 \mathrm{~L} / \mathrm{min}$ & $2 \mathrm{~L} / \mathrm{min}$ & $10 \mathrm{~cm} / \mathrm{min}$ & Constant i \\
\hline
\end{tabular}

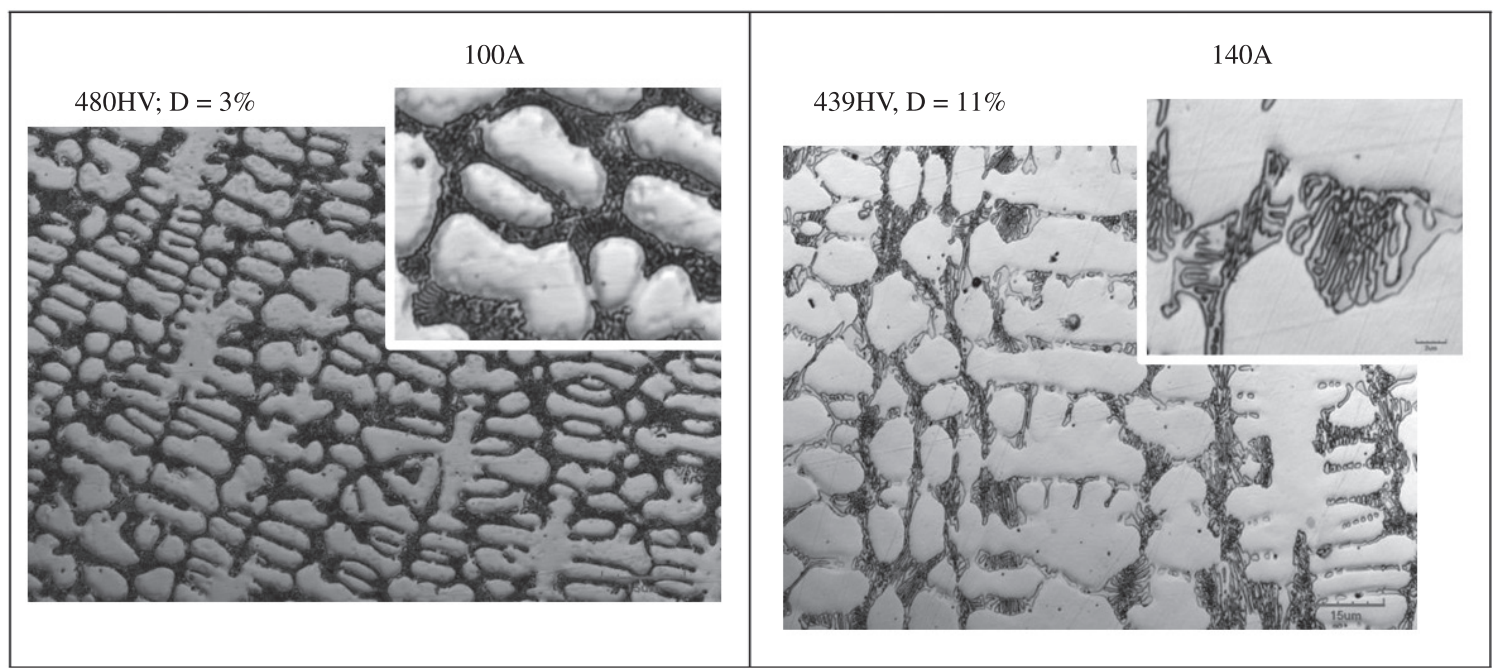

Figure 3. Effect of the deposition current on the coating microstructure, hardness (HV) and dilution (D).

All other processing parameters, given in Table 4, were kept constant.

Characterization of coatings included X-ray diffraction of the atomized alloy and at the top surface to identified eventual phase changes due to processing, laser confocal microscopy on the transverse section of coatings ( 3 to 3,6 $\mathrm{mm}$ thickness) was used to analyze microstructural changes as a consequence of the processing parameters and feedstock grain size. Changes in the microstructure can only be considered if they affected the coating hardness therefore, Vickers microhardness measurements (over 10 indentations) under load of $500 \mathrm{gf}$ were carried out on the transverse section of coatings, Figure 2.

Changes in the chemical composition of coatings were evaluated by the dilution with the substrate steel, carried out by the area ratio measured on the transverse cross section according to Equation 1.

$D=\frac{A}{A+B} \times 100$

where $\mathrm{A}$ is the melted area in the substrate and $\mathrm{B}$ is the overlay area.

\section{Results}

$\mathrm{X}$-ray diffraction analysis confirmed that for the conditions tested coatings exhibit the same phases as the atomized alloy, the $\operatorname{Co}(\alpha)$ solid solution and carbides. Therefore, once the dilution with the substrate is considered, variations in the microstructure can be assessed by the hardness of coatings.

The effect of increasing the deposition current on the microstructure as observed on the transverse section of coatings is shown in Figure 3. Coating hardness and dilution are also given.

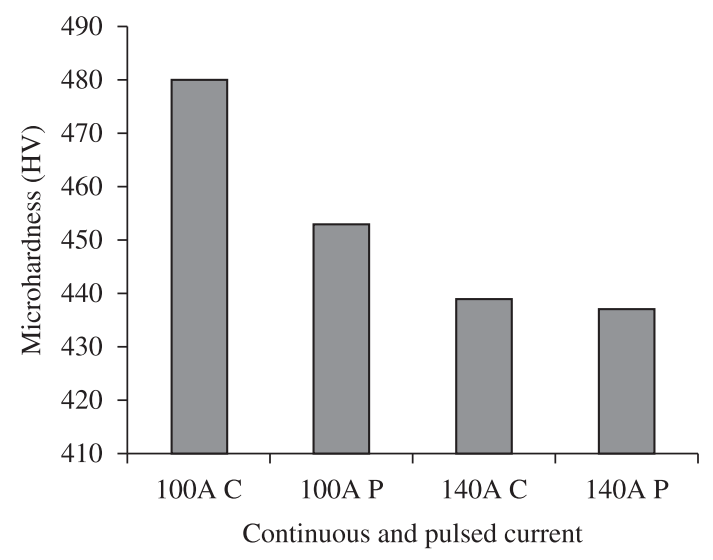

Figure 4. Effect of the current mode on the coating hardness (HV) and dilution (D).

Current mode also affected coatings as measured by hardness and dilution and illustrated in Figure 4.

The effect of the powder grain size, as $35 \mathrm{wt}$. (\%) of $45 \mu \mathrm{m}$ grains were mixed with the original grain size distribution, on the hardness of coatings processed with continuous current and their dilution is shown in Figure 5. Microstructures as observed in the transverse cross section of coatings are also shown.

\section{Discussion}

The higher temperature of particles as they cross the plasma arc, when processing with the higher deposition current can be assessed by the coarser structures exhibited by coatings processed with $140 \mathrm{~A}$. As a larger fraction of 


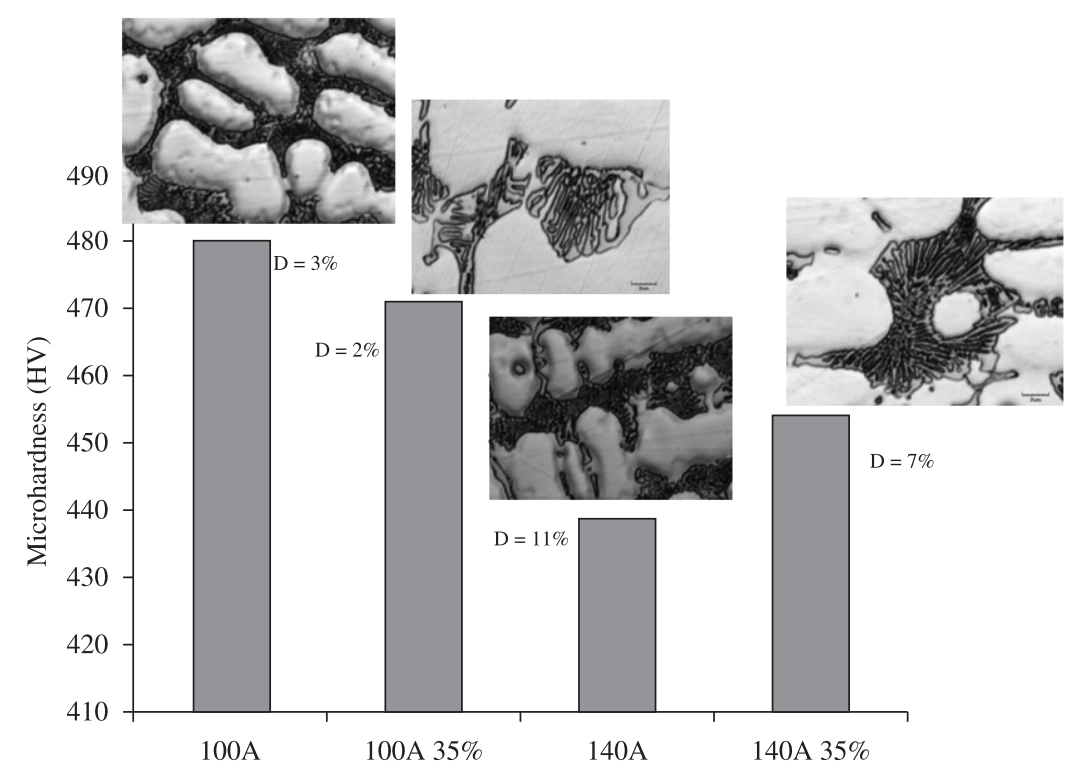

Figure 5. Effect of a higher fraction of finer particles on the hardness of coatings and corresponding microstructures and dilution (D).

particles reaches the melt pool with a higher temperature, their impact on the nucleation rate is smaller. The lower hardness of coatings processed with $140 \mathrm{~A}$ also agrees with the solidification of coarse structures in coatings. However, it is important to consider that the measured increase on dilution following the deposition with higher current also contributes to a reduction on hardness as it mainly refers to an increase in the Fe content of coatings ${ }^{8}$.

Hardfacing with a pulsed current has been shown to cause a hardness increase ${ }^{9-14}$ associated with a structure refinement as a more agitated pool can break secondary dendrite arms which will act as nuclei. However, in this study the measured hardness of coatings processed with the pulsed current is lower than that obtained when processing with a constant current of the same average intensity, Figure 4. Following the hypothesis put forward before regarding the role of the temperature of particles in the plasma arc on the solidification of coatings, it is suggested that the peak current caused an increase on the temperature that each particle reached in the plasma arc which resulted in their incorporation in the weld pool instead of acting as nuclei. The more significant hardness reduction of coatings processed with the average current of $100 \mathrm{~A}$ also includes the effect of the higher dilution exhibited by these coatings.

These results were also confirmed by the deposition of the feedstock with a higher fraction of finer particles. Finer grains are expected to reach a higher temperature in the plasma arc and subsequently be incorporated in the melt pool, resulting on coatings with coarser structures and lower hardness. Coatings processed with the lower current showed a small decrease in hardness when a higher fraction of finer particles is present, Figure 5. However, when processing with a higher current the higher fraction of fine particles in the atomized alloy resulted on coatings with a higher hardness. A significant contribution to the hardness increase can be attributed to the lower dilution of these coatings nevertheless it is also possible to consider that a fraction of the finer particles reached a higher temperature and evaporated in the plasma arc therefore will not contribute to the structure coarsening. Moreover, the energy used to evaporate the fine particles did not reach the substrate accounting for the lower dilution measured in these coatings.

\section{Conclusions}

Under the conditions tested it is possible to say that grain size distribution of the feedstock material should be considered a processing variable since there are evidences that:

- The temperature that each particle reaches in the plasma arc is determined by the deposition current and the particle size;

- During the solidification of coatings processed with an atomized feedstock alloy the nucleation stage predominates over the growth stage accounting for the finer microstructures observed;

- Coatings hardness is affected by the temperature of each particle when reaching the melt pool. Nevertheless dilution of coatings with the substrate also influences the coating hardness.

\section{Acknowledgements}

Thanks are due FINEP - Financiadora de Estudos e projetos, ANP and PRH24 for the financial support of this research work. 


\section{References}

1. Lugscheider E and Oberlander BCA. Comparison of the Properties of Coatings Produced by Laser Cladding and Conventional Methods. Materials Science and Technology. 1992; 8(8):657-665. http://dx.doi. org/10.1179/026708392790171134

2. D'Oliveira ASCM, Vilar R and Feder CG. High temperature behaviour of plasma transferred arc and laser Co-based alloy coatings. Applied Surface Science. 2002; 201:154-160. http:// dx.doi.org/10.1016/S0169-4332(02)00621-9

3. Klimpel A, Dobrzaski LA, Lisiecki A and Janicki D. The study of the technology of laser and plasma surfacing of engine valves face made of $\mathrm{X} 40 \mathrm{CrSiMo10}-2$ steel using cobalt-based powders. Journal of Materials Processing Technology. 2006; 175(1-3):251-256. http://dx.doi. org/10.1016/j.jmatprotec.2005.04.050

4. Buchanan VE, McCartney DG and Shipway PH. A comparison of the abrasive wear behaviour of iron-chromium based hardfaced coatings deposited by SMAW and electric arc spraying. Wear. 2008; 264(7-8):542-549. http://dx.doi. org/10.1016/j.wear.2007.04.008

5. Díaz VV, Dutra JC, Buschinelli AJA and D’Oliveira ASCM. Cavitation erosion resistance of deposits processed by plasma transferred arc welding. Welding International. 2009; 23:159-165. http://dx.doi.org/10.1080/09507110802543286

6. Silvério RB and D'Oliveira ASCM. Revestimento de liga a base de cobalto por PTA com alimentação de pó e arame. In: Proceedings of $2^{\circ}$ Congresso Brasileiro de Engenharia de Fabricação - COBEF; 2003; Uberlândia, Brasil. Uberlândia; 2003.

7. Silva RHG and Dutra JC. Processo PTA-P - Uma revisão da literatura como base para inovações. Parte 1 de 2: Elementos Construtivos. Soldagem e Inspeção. 2012; 17(1).
8. Yaedu AE and D'Oliveira ASCM. Cobalt based alloy PTA hardfacing on different substrate steels. Materials Science and Technology. 2005; 21(4):459-466. http://dx.doi. org/10.1179/174328405X36511

9. Sundaresan S and Ram GDJ. Madhusudhan Reddy,G. Microstructural refinement of weld fusion zones in $\alpha-\beta$ titanium alloys using pulsed current welding. Materials Science and Engineering. 1999; 262:88-100. http://dx.doi.org/10.1016/ S0921-5093(98)01010-7

10. Madhusudhan G, Reddy AA, Gokhale K and Rao P. Optimization of pulse frequency in pulsed current gas tungsten arc welding of aluminium-lithium alloy sheets. Materials Science and Technology. 1998; 14(1):61-66. http://dx.doi. org/10.1179/026708398790301746

11. Yamamoto H, Harada S, Ueyama T, Ogawaa S, Matsudab $\mathrm{F}$ and Nakatab K. Beneficial effect of low frequency pulsed MIG welding process on grain refinement of weld metal and improvement of solidification crak susceptibility for aluminium alloy. Journal of Light Metal Welding and Construction. 1993; 7:593-598.

12. Gokhale AA, Tzavaras AA, Brody HD and Ecer GM. Grain structure and hot cracking in pulsed current GTAW of AISI 321 stainless steel. Grain Refinement in Castings and Welds. 1983; 223-247.

13. Shinoda T, Ueno Y and Masumoto I. Effect of Pulsed Welding Current on Solidification Cracking in Austenitic Stainless Steel Welds. Transactions of the Japan Welding Society. 1990; 21(1):18-23.

14. Rao SRK, Reddy GM, Kamaraj M and Prasad Rao K. Grain refinement through arc manipulation techniques in $\mathrm{Al}-\mathrm{Cu}$ alloy GTA welds. Materials Science and Engineering. 2005; 404:227-234. http://dx.doi.org/10.1016/j.msea.2005.05.080 